\title{
Evaluation of the Effectiveness of 5\% Sodium Fluoride (NAF) with Diode Laser 976nm for Treatment of Dentine Hypersensitivity
}

\author{
IbtehalAtiaHabeeb ${ }^{1}$, Maha Sh. Mahmood ${ }^{2}$ \\ ${ }^{1}$ Post Graduate; ${ }^{2}$ Prof. Dr. Department of Periodontics College of Dentistry, University of Baghdad, Iraq
}

\begin{abstract}
Background: dentin hypersensitivity (DH) is a painful condition that is highly prevalent in the world's adult population.

Aim: The aim of this study was to compare the efficacy of fluoride varnish (5\% sodium fluoride)irradiation with diode laser in the treatment of dentin hypersensitivity in non caries cervical lesion(NCCL) patients.

Materials and Methods: Twenty patients with 90 teeth were divided into two groups: Group 1, teeth treated with diode laser with $5 \mathrm{~J} / \mathrm{cm} 2$ energy density; Group 2, teeth treated with $\mathrm{NaF}$ irradiated with diode laser with same previous diameter.
\end{abstract}

Results: The two treatments were applied to the buccalcervical region with three follow up intervals 30 minutes, 2 weeks and one month. The response of the patient to thermal-evaporative stimuli was rated on a Schiff cold air sensitivity scale. The results showed a reduction of hypersensitivity in response to thermalevaporative stimulation at the end of treatment in both groups.

Conclusion: dentine hypersensitivity treatment withNaF+diode laser was found to be more effective than low-level laser radiationimmediately.

Keywords: 5\% NaF,diode laser 976nm, DH; patients

\section{Introduction}

Dentine hypersensitivity (DH) is a communal painful clinical problem ascending from uncovered dentine, which cannot be ascribed to any other dental pathology. Under ordinary conditions, dentine is covered by enamel or cementum and is not affected by direct stimulation. Periodontal treatment such as scaling, root planing and also improper tooth brushing can expose root surfaces and may aggravate $\mathrm{DH}$. Although different theories have been anticipated for the mechanism of DH, with "hydrodynamic theory" the most commonly

\section{Corresponding author: \\ IbtehalAtiaHabeeb \\ Ibtehal19@gmail.com}

one ${ }^{[1]}$, assumes that painful stimulation increases fluid flow within the dentinal tubules inward and outward [2]. Then, it appears suitable to suppose that any materials or technique that decreases dentinal fluid movement should decrease dentine hypersensitivity ${ }^{[3]}$.Several techniques and materials such as dentifrices, mouthwashes, dentine adhesives, varnishes and restorative materials were tried to decrease $\mathrm{DH}$. Sodium fluoride $(\mathrm{NaF})$ formulations have been tried in vitro and in clinical examinations [4]. The using of $\mathrm{NaF}$ on hypersensitive tooth mostly results inobliteratepatent dentinal tubules as resulted of precipitation of calcium fluoride crystals consequently control the permeabilityof exposed dentine according to hydrodynamic theory ${ }^{[5]}$. Another treatment methodology for $\mathrm{DH}$ was established with the appearance of laser technology that is progressively utilized in dentistry 
[6].The lasers utilized for the treatment of sensitive teeth according to output powers couldbe dividedin two groups: The low-level lasers are helium-neon (He-Ne) and gallium- aluminum arsenide (GaAlAs) (diode) lasers and The middle output power lasers are neodymium doped: yttrium, aluminum, and garnet (Nd:YAG); erbium doped: YAG (Er:YAG); and carbon dioxide $(\mathrm{CO} 2)$ lasers $^{[7]}$. The effect of laser irradiation on dentine surface have explain by several theories, however for the middle output lasers the most acceptable one shows that sealing or occluding the dentinal tubules by melting and re-crystallization of dentine ${ }^{[6]}$.Newly, low-level laser therapy (LLLT) proved by studies can impede dentinal tubules by expanding the cell metabolic movement ofodontoblasts that encourage deposition of tertiary dentine[8].On the other hand, review of literature showed that there areno published data available regardingthe desensitizingeffect of single application of diode laser with 976 wave length for patients with non caries cervicallesions (NCCLs).The aim of this randomized, controlled, clinical study is to compare diode laser alone withdiode laser of 976 wave length in combination with $5 \%$ sodium fluoride application in the treatment of DHfollowing scaling.

\section{Subjects and Methods}

Twenty patients ( 8 men and 12 women; 90 teeth) between the ages of 25 and 50 affected by DH were selected for this study. After having oral and written information about the designof the study, informed consent form have been taken from all patients. Study protocol andrelated consent forms were approved by ethical committee/ college of Dentistry/ University of Baghdad, followed the guidelines of Helsinki and Tokyo for humans (the reference no. 130619 in 2\12\2019).

\section{Inclusion criteria}

To be included in the study, the patients had to have NCCLs (erosion, abrasion, attrition and abfraction) suffering of dentine hypersensitivity have four or more hypersensitive teeth at different quadrants ${ }^{[9]}$.

\section{Exclusion criteria}

Criteria for exclusion from the study were using of desensitizing toothpaste in the last 3 months, any professional desensitizing therapy on the selected teeth during the last 6 months, defective restorations, carious lesionson the selected or neighboring teeth, taking analgesics/anti-inflammatorymedications at the time of the study, pregnancy, and smoking ${ }^{[7]}$.

\section{DH assessment}

Before the application of diode laser and diode $+\mathrm{NaF}$ varnish, DH was assessed by an evaporative stimulus -Schiff cold air sensitivity scale ${ }^{[10]}$. A cold air-blast from a dental syringe was directed to the exposed cervical area for 3 secs at a distance of $2 \mathrm{~mm}$ at a right angle to the buccal site of the assigned teeth, while the adjacent teeth were isolated with cotton rolls and operator's fingers. The scale includes the following scores:

0- Tooth/subject did not respond to the air stimulus.

1- Tooth/subject responded to the air stimulus but did not request discontinuation of the stimulus.

2- Tooth/subject responded to the air stimulus and requested discontinuation or moved from the stimulus.

3- Tooth/subject responded to the air stimulus, considered the stimulus to be painful, and requested discontinuation of the stimulus.

\section{Treatment modalities}

In this split-mouth study design for each patient, selected teeth were randomly assigned to the diode laser group and diode +NAF. Adjacent teeth received the same treatment however, the teeth of the different quadrants received different treatment desensitizers. The diode laser used in this clinical was SOLAS dental diode laser which is a surgical and therapeutic device produced by Lazon medical laser Company with continuous emission (976 nm) on non-contact mode $(0.5 \mathrm{~mm}$ from the surface). The laser device was used with the following parameters: output power of $0.6 \mathrm{~W}$, the irradiation time of $60 \mathrm{sec}$ using 400 tip diameters. 
The laser was applied by scanning the cervical part in an intersecting pattern. In the $\mathrm{NaF}$ varnish group (Alphapro white fluoride varnish made in the USA), the light white varnish was applied with a disposable brush at the cervical region of the buccal surface, ensuring dry tooth surface by isolation with cotton rolls and an air syringe. The varnish left on the tooth surface about 60 secs before laser irradiation with the same previous diameter. After one-minute, material removed from the tooth surface, DH was assessed using the Schiff scale immediately after 30 minutes, 2 weeks, and at 1 month after treatments by a single examiner. All patients used a soft toothbrush and a toothpaste without any anti-hypersensitivity agent.

\section{Statistical Analysis}

The data were entered in Microsoft Excel and statistical analysis were performed using the Statistical Package for Social Science (SPSS version 25) software. Independent sample -t-test used to test the difference between two groups.

\section{Results}

Table 1 showed the reduction of mean in diode laser group from 2.24 before treatment to 0.71 after one month, however in $\mathrm{Naf}+$ diode laser group the reduction of mean was 2.33 before treatment to 0.02 after one month.Highly significant differences can be observed immediately after treatment $(30 \mathrm{~min}) \mathrm{p}$ value $=0.00$ compared with that before treatment where the $p$ value $=0.52$.

Table 1:Comparison between study groups using independent sample t- test

\begin{tabular}{|c|c|c|c|c|c|c|c|c|c|}
\hline & & & & & \multicolumn{5}{|c|}{ Independent sample t-test } \\
\hline $\mathrm{C}=\mathrm{r}$ & \multicolumn{2}{|c|}{ laser } & \multicolumn{2}{|c|}{ Laser+Naf } & \multicolumn{2}{|c|}{$95 \%$ confidence interval } & \multirow[b]{2}{*}{ t-test } & \multirow[b]{2}{*}{ df } & \multirow[b]{2}{*}{ P-value } \\
\hline & Mean & SD & Mean & SD & lower & Upper & & & \\
\hline Before treatment & 2.24 & 0.71 & 2.33 & 0.73 & 0.39 & 0.21 & 0.58 & 88 & 0.52 \\
\hline After 30 minute & 0.80 & 0.40 & 0.24 & 0.43 & 0.38 & 0.73 & 6.27 & 88 & 0.00 \\
\hline After 2 week & 0.73 & 0.44 & 0.02 & 0.14 & 0.57 & $\mathrm{O} .85$ & 10.11 & 88 & 0.00 \\
\hline After one month & 0.71 & 0.45 & 0.02 & 0.14 & 0.54 & 0.83 & 9.58 & 88 & 0.00 \\
\hline
\end{tabular}

\section{Discussion}

$\mathrm{DH}$ is a common, painful sensation for patientswhohave NCCL.Satisfactory results have been shown with multiple treatments, there is still no best quality level for the treatment of DH accessible today ${ }^{[11]} \mathrm{NaF}$ varnish is mainly used in clinical studies. In the present study, 5\% NaF was chosen as a desensitizing agent, however studies showed that topical application of $\mathrm{NaF}$ exerts a desensitizing effect on exposed dentine and cementum $^{[12]}$. The reaction between $\mathrm{NaF}$ and calcium ions that leads to formation of calcium fluoride crystals, which are deposited on the dentinal tubules' openings [13]. The effectiveness of the Nd:YAG laser and 5\% 
$\mathrm{NaF}$ varnish inthe management of $\mathrm{DH}$ was evaluated by Kumar and Mehta both clinically and under the scanning electron microscopy (SEM). The authors exhibited that both of the treatment ways are effective in the treatment of $\mathrm{DH}^{[14]}$

In this clinical study, an attempt was made to evaluate effectiveness of diode laser with and without $5 \% \mathrm{NaF}$ in treatment of dentine hypersensitivity. The effectiveness of LLLT on DH was evaluating in many vitro and vivo studies. The dosage and the amount of energy applied are important factors in the effectiveness of LLLT in addition to the wavelength. These lasers provide an immediate analgesic effect by depressing nerve transmission [6]. Based on the physiological experiments, this immediate effect of a GaAlAs laser is caused by blocking the depolarization of $\mathrm{C}$-fiber afferents ${ }^{[15]}$. Sicilia et al. assessed the instant effectiveness in the reduction of $\mathrm{DH}$ in periodontal patients. They reported that LLLT has shown rapid DH reduction compared to the placebo laser in periodontal patients ${ }^{[16]}$. Consistent with this report, in this clinical trial, boththe diode laser+ $\mathrm{NaF}$ varnish and diode laseralone had a desensitizing effectimmediately (30 minutes) after a single application. In addition to theimmediate analgesic effect. The laser therapy applied with

correct parameters may stimulate the cellular metabolic activity of the odontoblasts and obliterate the dentinal tubules with the intensification of tertiary dentine production ${ }^{[8]}$.

In this clinical trial,solase diode laser was used with wavelength 976 with an optical fiber (400 mm diameter), $0.6 \mathrm{w}$ in non-contact mode for 60 seconds. Currently, several studies have reported that the application of $980 \mathrm{~nm}$ diode laser could be used safely in endodontic treatment and in root canal disinfection [17]. The present study showed that significant reduction in the level of DH in group one to thermal-evaporative stimuli using Schiff scale and showed a reduction of the mean from 2.22 before treatment to 0.8 after treatment and these results remain stable up to one month. This was in agreement with most studies using the same parameter. In a similar study a galium: aluminum: arsenide (GaAlAs) diode laser used was a 970nm wavelength laser with an optical fiber (200 $\mathrm{mm}$ diameter). The specimenwas irradiated with a frequency of $10 \mathrm{~Hz}$ contact mode for 30 seconds [18]. Results showed good dentinal tubules occlusion.

Although diode laser irradiation at a power of $60 \mathrm{~mW}$ does not have morphological effect on the surface of enamel or dentine, however this small fraction of the laser energy is transmitted through dental hard tissues to extent the pulp [6]. In our study, the results of combination treatment of NAF+ Diode laser group showed a significant reduction of dentine hypersensitivity by mean of 2.33 before treatment to 0.24 after 30 minutes and this results remain stable after one month. These results agree with other studies using the same type of therapy [19].Further studies are necessary to evaluate the morphological changes of the dental hard tissues under SEM after diode laser (976) irradiation for DH treatment.

\section{Conclusion}

dentine hypersensitivity treatment with $\mathrm{NaF}+$ diode laser was found to be more effective than low-level laser radiation immediately

Ethical Clearance: The Research Ethical Committee at scientific research by ethical approval of both MOH and MOHSER in Iraq

\section{Conflict of Interest: None}

Funding: Self-funding

\section{References}

1. Bra nnstro"m, M. Sensitivity of dentine. Oral Surg. Oral Med. Oral Pathol. (1966). 21,517-526.

2. Holland G, Narhi MN, Addy M, Gangarosa L, Orchardson R. Guidelines for the design and conduct of clinical trials on dentine hypersensitivity. Journal of clinical periodontology. 1997 Nov;24(11):80813.

3. Orchardson R, Gillam DG. Managing dentin hypersensitivity. The Journal of the American Dental Association. 2006 Jul 1;137(7):990-8. 
Medico-legal Update, October-December 2021, Vol.21, No. 4

4. Ipci SD, Cakar G, Kuru B, Yilmaz S. Clinical evaluation of lasers and sodium fluoride gel in the treatment of dentine hypersensitivity. Photomedicine and laser surgery. 2009 Feb 1;27(1):85-91.

5. Al-Sabbagh M, Brown A, Thomas MV. In-office treatment of dentinal hypersensitivity. Dental Clinics of North America. 2009 Jan 1;53(1):47-60.

6. Kimura Y, Wilder $\square$ Smith P, Yonaga K, Matsumoto $\mathrm{K}$. Treatment of dentine hypersensitivity by lasers: a review. Journal of Clinical Periodontology: Review article. 2000 Oct;27(10):715-21.

7. Dilsiz A, Canakci V, Ozdemir A, Kaya Y. Clinical evaluation of $\mathrm{Nd}$ : YAG and $685-\mathrm{nm}$ diode laser therapy for desensitization of teeth with gingival recession. Photomedicine and Laser Surgery. 2009 Dec 1;27(6):843-8.

8. Ferreira AN, SilveiraJr L, Genovese WJ, De Araujo VC, Frigo L, De Mesquita RA, Guedes E. Effect of GaAIAs laser on reactionaldentinogenesis induction in human teeth. Photomedicine and Laser Therapy. 2006 Jun 1;24(3):358-65.

9. SCHWARZ, Frank, et al. Desensitizing effects of an Er: YAG laser on hypersensitive dentine: a controlled, prospective clinical study. Journal of Clinical Periodontology, 2002, 29.3: 211-215.

10. Schiff T, Delgado EV, Zhang YP, Cummins DI, DeVizio W, Mateo LR. Clinical evaluation of the efficacy of an in-office desensitizing paste containing $8 \%$ arginine and calcium carbonate in providing instant and lasting relief of dentin hypersensitivity. American journal of dentistry. 2009 Mar 1;22(Spec No. A):8A-15A.

11. Porto IC, Andrade AK, Montes MA. Diagnosis and treatment of dentinal hypersensitivity. Journal of oral science. 2009;51(3):323-32.

12. Orsini G, Procaccini M, Manzoli L, Giuliodori F, Lorenzini A, Putignano A. A double-blind randomized-controlled trial comparing the desensitizing efficacy of a new dentifrice containing carbonate/hydroxyapatite nanocrystals and a sodium fluoride/potassium nitrate dentifrice. Journal of clinical periodontology. 2010 Jun;37(6):510-7.

13. Komabayashi $\mathrm{T}$, Imai $\mathrm{Y}$, Ahn $\mathrm{C}$, Chow LC, Takagi S. Dentin permeability reduction by a sequential application of calcium and fluoridephosphate solutions. Journal of dentistry. 2010 Sep 1;38(9):736-41.

14. Kumar NG, Mehta DS. Short-term assessment of the Nd: YAG laser with and without sodium fluoride varnish in the treatment of dentin hypersensitivity-a clinical and scanning electron microscopy study. Journal of periodontology. 2005 Jul;76(7):1140-7.

15. Wakabayashi H, Hamba M, Matsumoto K, Tachibana $\mathrm{H}$. Effect of irradiation by semiconductor laser on responses evoked in trigeminal caudal neurons by tooth pulp stimulation. Lasers in surgery and medicine. 1993;13(6):605-10.

16. Sicilia A, Cuesta-Frechoso S, Suárez A, Angulo J, Pordomingo A, De Juan P. Immediate efficacy of diode laser application in the treatment of dentine hypersensitivity in periodontal maintenance patients: a randomized clinical trial. Journal of clinical periodontology. 2009 Aug;36(8):650-60.

17. Faria MI, Sousa-Neto MD, Souza-Gabriel AE, Alfredo E, Romeo U, Silva-Sousa YT. Effects of 980-nm diode laser on the ultrastructure and fracture resistance of dentine. Lasers in medical science. 2013 Jan 1;28(1):275-80.

18. Rizzante FA, Maenosono RM, Duarte MA, Furuse AY, Palma-Dibb RG, Ishikiriama SK. In Vitro evaluation of dentin hydraulic conductance after $980 \mathrm{~nm}$ diode laser irradiation. Journal of periodontology. 2016 Mar;87(3):320-6.

19. Yilmaz HG, Kurtulmus-Yilmaz S, Cengiz E. Longterm effect of diode laser irradiation compared to sodium fluoride varnish in the treatment of dentine hypersensitivity in periodontal maintenance patients: a randomized controlled clinical study. Photomedicine and laser surgery. 2011 Nov 1;29(11):721-5 . 